\title{
THE BELL TOLLS FOR THE RELATIONSHIP BETWEEN HOUSE DUST MITE EXPOSURE AND ASTHMA IN CHILDHOOD
}

\author{
Catarina Almqvist*, ${ }^{*}$, Guy Marks ${ }^{\#}$, Qiang Li ${ }^{\#}$, Daniel Crisafulli ${ }^{\#}$ and Euan Tovey \\ Paediatric Respiratory Epidemiology Abstract Award, sponsored by Scherig AG \\ *Dept of Medical Epidemiology and Biostatistics and Dept of Woman and Child Health, Karolinska Institutet, Stockholm, Sweden \\ \#Epi Group, Woolcock Institute of Medical Research, Sydney NSW, Australia
}

WINNING ABSTRACT: Prior evidence has suggested a direct relationship between the level of house dust mite (HDM) allergen exposure, sensitisation and asthma. A recent cross-sectional study indicated a bell-shaped relationship between HDM exposure and sensitisation [1]. We examined the effects of cumulative HDM allergen exposure during the first 5 years of life on outcomes at age 5 years in Sydney, a high HDM environment.

In the Childhood Asthma Prevention Study, bed dust samples collected at 3, 6, 9 and 12 months and then 6-monthly (total 6615 samples) until age 5 years were analysed for HDM allergen by ELISA. At five years, 516 children were assessed for wheeze and asthma by questionnaires and spirometry, and 488 for sensitisation by skin test. Time-weighted average HDM allergen concentration was estimated for each individual. The range was divided into quintiles with cut-points being 3,$5 ; 7,8 ; 13,5$ and 23,4 ug Der p 1/g. The association between HDM levels and outcomes was analysed with chi-square test, adjusting for confounders.

The figure shows the prevalence of outcomes by quintile of time-weighted average of HDM allergen.

In this birth cohort, there is a bell-shaped dose response between HDM levels and sensitisation and asthma. This may reflect tolerance to HDM allergen or be attributable to protection from associated exposures, and prompts further research on the mechanisms.

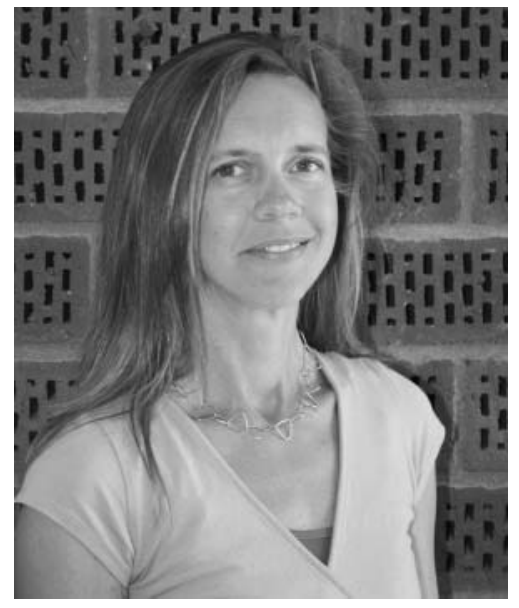

Catarina Almquist

Dept of Medical Epidemiology and Biostatistics and Dept of Woman and Child Health, Karolinska Institutet, Stockholm, Sweden

\section{MY RESEARCH AND HOW MY WINNING ABSTRACT IS PART OF THIS}

The major theme of my research has been environmental epidemiology, assessing the risk factors for asthma and allergic diseases in childhood. The publications in my PhD thesis examined dispersal of cat allergen borne on clothing from homes with cats and taken to schools and clothing from homes without cats [2] and evaluated how this indirect cat exposure

STATEMENT OF INTEREST: None declared. at school affects asthmatic children with cat allergy [3]. Moreover, based on a large Swedish birth cohort (BAMSE; Children Allergy Environment in Stockholm - an Epidemiological study) with selection for pet ownership [4], risk associations between early exposure to cat and dog and later asthma and allergic disease were assessed [5]. My PhD thesis entitled "Cat and dog allergens: dispersal, exposure and health effects in childhood" was presented at Karolinska Institutet (Stockholm, Sweden) in December 2002 and was followed by other scientific papers $[6,7]$.

Since my PhD I have been involved in additional studies from the BAMSE cohort, assessing environmental risk factors for asthma and allergic disease, such as exposure to environmental tobacco smoke, effects of breast feeding, socioeconomic status and obesity [8-11]. I have also been involved in the European Global Asthma and Allergy European Network ( $\mathrm{Ga}_{2}$ len) network as the Karolinska Institutet representative in the Gender WP 2.5. My main task has been to review studies on sex differences in asthma and allergic diseases in childhood [12], and I have initiated collaboration with the Birth Cohort WP 1.5 , to identify questions to assess stages of puberty in future birth cohort questionnaires, which will allow future analyses of larger populations.

From September 2004 until February 2007, I was a visiting postdoctoral research fellow at the Woolcock Institute of Medical Research (Sydney, Australia). I was mainly working on the Childhood Asthma Prevention Study (CAPS), which is a randomised controlled trial of house dust mite avoidance and dietary interventions for the prevention of asthma, implemented from birth in a cohort of 516 children at high risk of developing asthma. This study tested the effect of house dust mite avoidance and increasing the ratio of omega- 3 to omega- 6 
long-chain polyunsaturated fatty acids in the diet from birth to age 5 yrs. The study found that neither of these interventions had any beneficial effect on the prevalence of asthma or allergic disease at age 5 yrs [13]. My winning abstract is a post hoc analysis of data from this study, examining the relationship between mite allergen exposure during the first 5 yrs of life and risk of asthma and sensitisation at age $5 \mathrm{yrs}$, including the shape of the dose-response relationship of various measures of house dust mite allergen exposure.

\section{MY RESEARCH AS PART OF MY WORKING GROUP/ RESEARCH TEAM}

This fits well into the main research area of the epidemiology group at Woolcock Institute of Medical Research. The group conducts research that describes the prevalence of respiratory disease, risk factors for the development or remission of respiratory disease, and investigates interventions to reduce the burden of asthma and other respiratory diseases. Members of the group have skills in statistics and database management. A number of other important analyses of the data from this CAPS cohort include: examining the time course of atopy, eczema and asthma/rhinitis during early childhood [14]; describing seasonal and climatic variation in house dust mite allergen levels [15]; exploring changes in immunological profiles during the first 5 yrs of life [16]; assessing the impact of duration of breast feeding and other infant feeding practices [17]; possession of cats and dogs; and levels of fatty acids in the blood and the diet on the incidence of allergic disease during early childhood [18]; and describing the incidence of snoring in children with rhinitis [19]. In the group, there was also a lot of creative thinking about alternative explanations to the "hygiene hypothesis", which has produced a number of new research questions [20]. It was a very rewarding experience to undertake research as a postdoctorate in a new and creative environment, and I am now in the process of developing plans for future research projects in Sweden.

\section{MY JOB AND THE ROLE OF THE UNIT IN WHICH I WORK}

I have recently taken up a practitioner fellowship in paediatrics at the Astrid Lindgren Children's Hospital (Stockholm). This will allow me to carry out part-time clinics, mainly at the Unit of Respiratory and Allergic diseases, and part-time research. The unit is part of the Paediatric Division at the Karolinska University Hospital and the regional centre for children with asthma and allergic diseases, as well as paediatric lung diseases. It is also the national referral centre for severe asthma, complicated lung diseases, cystic fibrosis and specific immune therapy. The unit has four paediatric allergists and 2.5 paediatric pulmonologists, as well as three paediatricians in the cystic fibrosis team. Each week, 130-150 patients visit the unit, which has equipment for dynamic spirometry and measurements of exhaled nitric oxide fraction as well as the possibility for bronchial provocations and allergy testing. In the unit, approximately three to four bronchoscopies are performed each week and there a large number of children and adolescents (160-200 patients) who undertake immunotherapy, mainly towards birch, grass and cat allergens. Connected to the unit is a ward where food provocations are undertaken (5-10 per week), and a weekly average of three to four respiratory/allergy patients are admitted. Respiratory and asthma problems in other wards, such as the infectious diseases or intensive care units, are also looked after by us as consultants, and we work together with gastroenterologists, cardiologists, endocrinologists and paediatric surgeons, as well as social workers, child psychiatrists, physiotherapists and dieticians.

My research is mainly undertaken at the Dept of Medical Epidemiology and Biostatistics at Karolinska Institutet, a department with a wide range of epidemiological research. The projects generally aim to increase knowledge about the causes of diseases and disseminate clinical and genetic research, as well as biostatistical methodology. The research is based on information collected through questionnaires, interviews, medical records, different types of registers and samples. The department has $\sim 150$ researchers, doctoral students, statisticians, programmers, data collectors, database administrators and administrative staff. The Karolinska Institute Biobank is also located with the department and the department is responsible for the Swedish Twin Registry. I will be heavily involved in clinical and epidemiological research on risk factors for paediatric asthma and allergy, and will take part in setting up a large national cohort. Characteristics of this cohort are regular assessment of exposure information, regular surveillance of morbidity, repeated collection of DNA and other biological samples, links with national registers and state-of-theart biobanking of 500,000 Swedish people aged 0-50 yrs.

\section{THE IMPACT OF MY WORK ON CLINICAL OR RESEARCH PRACTISE}

The burden of illness due to asthma and allergic diseases is substantial. While disease management strategies play an important role in reducing the burden of asthma, it is highly desirable to explore opportunities for environmental modification to prevent the onset or progression of the disease. Our data provide powerful insights into early life origins and evolution of asthma and other allergic illness, as well as sex differences in avoidable environmental factors that could be targets for public health interventions to prevent and reduce the burden of asthma and allergic diseases in childhood and adolescence.

\section{REFERENCES}

1 Schram-Bijkerk D, Doekes G, Boeve M, et al. Nonlinear relations between house dust mite allergen levels and mite sensitization in farm and nonfarm children. Allergy 2006; 61: 640-647.

2 Almqvist C, Larsson PH, Egmar AC, Hedren M, Malmberg P, Wickman M. School as a risk environment for children allergic to cats and a site for transfer of cat allergen to homes. J Allergy Clin Immunol 1999; 103: 1012-1017.

3 Almqvist C, Wickman M, Perfetti L, et al. Worsening of asthma in children allergic to cats, after indirect exposure to cat at school. Am J Respir Crit Care Med 2001; 163: 694-698.

4 Almqvist C, Egmar AC, van Hage-Hamsten M, et al. Heredity, pet ownership, and confounding control in a population-based birth cohort. J Allergy Clin Immunol 2003; 111: 800-806.

5 Almqvist C, Egmar AC, Hedlin G, et al. Direct and indirect exposure to pets-risk of sensitization and asthma at 4 years in a birth cohort. Clin Exp Allergy 2003; 33: 1190-1197. 
6 Almqvist C, Hage-Hamsten M. Cat and dog allergens-can intervention studies solve their inscrutable riddle? Clin Exp Allergy 2003; 33: 1167-1170.

7 Almqvist C. High allergen exposure as a risk factor for asthma and allergic disease. Clin Rev Allergy Immunol 2005; 28: $25-42$.

8 Wickman M, Melen E, Berglind N, et al. Strategies for preventing wheezing and asthma in small children. Allergy 2003; 58: 742-747.

9 Kull I, Almqvist C, Lilja G, Pershagen G, Wickman M. Breast-feeding reduces the risk of asthma during the first 4 years of life. J Allergy Clin Immunol 2004; 114: 755-760.

10 Almqvist C, Pershagen G, Wickman M. Low socioeconomic status as a risk factor for asthma, rhinitis and sensitization at 4 years in a birth cohort. Clin Exp Allergy 2005; 35: 612-618.

11 Mai XM, Almqvist C, Nilsson L, Wickman M. Birth anthropometric measures, body mass index and allergic diseases in a birth cohort study (BAMSE). Arch Dis Child 2007; 92: 881-886.

12 Almqvist C, Worm M, Leynaert B, Working Group of GA2LEN WP 2.5 Gender. Impact of gender on asthma in childhood and adolescence: a $\left.\mathrm{GA}_{2} \mathrm{2}\right) \mathrm{LEN}$ review. Allergy 2008; 63: 47-57.

13 Marks GB, Mihrshahi S, Kemp AS, et al. Prevention of asthma during the first 5 years of life: a randomized controlled trial. J Allergy Clin Immunol 2006; 118: 53-61.
14 Almqvist C, Li Q, Britton WJ, et al. Early predictors for developing allergic disease and asthma: examining separate steps in the "allergic march". Clin Exp Allergy 2007; 37: 1296-1302.

15 Crisafulli D, Almqvist C, Marks G, Tovey E. Seasonal trends in house dust mite allergen in children's beds over a 7-year period. Clin Exp Allergy 2007; 62: 1394-1400.

16 Weber-Chrysochoou C, Crisafulli D, Almqvist C, et al. IL-5 $\mathrm{T}$-cell responses to house dust mite are associated with the development of allergen-specific $\operatorname{IgE}$ responses and asthma in the first 5 years of life. J Allergy Clin Immunol 2007; 120: 286-292.

17 Mihrshahi S, Ampon R, Webb K, et al. The association between infant feeding practices and subsequent atopy among children with a family history of asthma. Clin Exp Allergy 2007; 37: 671-679.

18 Almqvist C, Garden F, Xuan W, et al. Omega-3 and omega6 fatty acid exposure from early life does not affect atopy and asthma at age 5 years. J Allergy Clin Immunol 2007; 119: 1438-1444.

19 Marshall NS, Almqvist C, Grunstein RR, Marks GB. Predictors for snoring in children with rhinitis at age 5 . Pediatr Pulmonol 2007; 42: 584-591.

20 Tovey ER, Kemp AS, Almqvist C, Sharland A, Marks GB. Do immune responses to inhaled skin flakes modulate the expression of allergic disease? Clin Exp Allergy 2007; 37: 1199-1203. 